\title{
AN EFFECTIVE ENGLISH CLASS WITH APPROPRIATE TECHNIQUES AND STRATEGIES
}

\author{
Vahidije Kadiu ${ }^{1}$, Tomi Treska ${ }^{2}$
}

\begin{abstract}
Teaching is considered to be one of the most important aspects for the future of the human beings. The fact that teaching is an art based on techniques and strategies is very important. The aim of this paper is to study the appropriate techniques and strategies for an effective English class. To achieve this, a survey was conducted at "Asim Vokshi secondary school. The main instrument used was a questionnaire. It was conducted on 70 students and 70 teachers. According to the results of the survey, many teachers believe that during an English class, different techniques and strategies should be included such as: cooperation, control of the class, and motivation. They also stressed the fact that four skills should be co-related for an effective class. The most important finding was related to the students. According to them, the best way to learn the English language was by writing.
\end{abstract}

UDC Classification: 373, DOI: http://dx.doi.org/10.12955/cbup.v4.818

Keywords: teacher's role, activities, skills, strategies and techniques.

\section{Introduction}

Teaching is a process intended for learning by inducing a behavioral change in the taught. It is an art of communicating a message with impact on the audience. Noddings (2003) states that: "teaching is never more than a means". According to Noddings (2003), teaching is not a practice in itself, although it serves other practices. Teaching is never more than a means where all students can learn. Teaching is more effective when teachers and trainers, articulate a clear set of the objectives, or competencies and provide opportunities for students to demonstrate and practice the knowledge and skills of the objectives, or competencies. It also requires adapting. We need to reflect on our teaching and be ready to make changes when appropriate. All teachers change with their experiences in and out of the classroom. According to UKEssays (2015) "A teacher needs to be able and capable to motivate, inspire and get the best effort out of a student". Teaching is a process that develops and changes over time. According to Noddings (2003), many debates focus on the question of whether teaching implies learning. It can be compared to selling commodities. No one can sell unless someone buys. It is pointed out that teaching is an activity that finds its result in the learner, not in the teacher. Where there is no need for learning, there would be no need for teaching. This doesn't mean that teaching must always produce learning, but it must be constructed around the perceived need for learning.

Effective Class with appropriate techniques and strategies

We face many problems when working with children and the youth. Providing them with feedback is considered very important these days. To be successful, teachers need to have effective strategies and techniques in realizing our objective. It is important to mention here that techniques and strategies have changed over time. We no longer can use some of the techniques and strategies that we used when we were their their age. The teacher is responsible for the techniques he/she uses in class. Greive (1992) mentions the following strategies of effective teachers:

- They establish good control on the class. They know exactly what to do at the right moment.

- They do things right, which means they pay sufficient attention to the whole class, concentrate on every student who is speaking and clarify any misunderstanding that may occur during the lesson.

- They have positive expectations from all students.

- They establish good classroom management techniques.

- They work in cooperation and learn from colleagues.

- They designs lesson for students.

\footnotetext{
${ }^{1}$ Vahidije Kadiu, European University of Tirana, Department of Education, Tirana, Albania vahidije.kadiu@uet.edu.al

${ }^{2}$ Tomi Treska, Head of the Department of Education, European University of Tirana, Tirana, Albania tomi.treska@uet.edu.al
} 
- They realize that teaching is not a private practice.

- They are flexible and adaptable.

- They understand the process of learning.

- They teach with proven research - based practices.

- They know the difference between an effective teacher and an ineffective one.

Some strategies suggested by BUC (2012) for teachers to use are:

On the first day, they should introduce themselves and avoid the predictable ways of starting a class like good morning, we talked about, etc. They should begin with a provocative question or current event, ask someone in the class to summarize what happened in the last class, set up a problem with a promise that they will be given a solution by the end of the class, and plan a lecture to be covered in less than the entire period. Usually, questions take up more time than teachers expect so they should decide what is important, essential, and what is helpful. They should be conversational, be themselves, and speak naturally. They should use gestures to emphasize points as gestures are considered to be a mirror of the teacher's voice. They should repeat critical points if necessary and use appropriate tones when speaking to stress the important points. They should pause before making new points and look at the audience. They can try out techniques that they admire in others and ask students to consider issues with the person sitting next to them which are then discussed with the whole group. They should use the board if necessary, answer questions as directly as possible and ask the students to spend the last five minutes writting down the most important things they learnt. According to the University of Phoenix (2011), another important point to mention is the classroom management which includes all the things that a teacher does to organize students, space, time and materials so that instruction in content and student learning can take place. This method includes teaching expectations, which means what, how, and when expectations will be taught. Weimer (2009) mentions two major goals involved:

- to foster student involvement and cooperation in all classroom activities, and

- to establish a productive working environment.

Good planning is an important step in organizing an effective class. The desk arrangement can be as follows:

Desk in rows, front to back: this is the traditional way of arranging desks in Albania, and this kind of arrangement is mostly effective whenever students have exams which entails individual work.

Desks in U-shape: this is mostly used in the western countries and is effective when students have discussion or debates in the class according to the topic. Teachers should take into consideration:

- to keep the number of students per class minimum (20 students if possible),

- to keep the wording simple, and

- use attentive materials. They can decide upon a signal to get students' attention and teach students to respond to that signal by focusing on them and maintaining complete silence. For example with "hand risen", they might say: "Can I have your attention please". This prompts all students to stop, look at the teacher and raise their hand. Advantages of this method are:

- it can be used from any location in the room,

○ it can be used outside the classroom, and

0 it has both a visual and auditory component.

According to Keith, Pritchard and Roesch (2008), while some students shine with these qualities others dont. Some students show enthusiasm, optimism, curiosity and interest, whereas disaffected students are passive, do not try hard and give up easily. Classrooms are composed of both affected and disaffected students. The focus of the teacher should be in changing the negative attitudes and behavior of their students, and motivating them to take part in the class. Mendler (2000) provides strategies to motivate students under the assumption that every student who is capable of learning will be motivated when adults treat them with care and respect. The authors believes that teachers can motivate students who don't care by applying five key aspects:

- Emphasizing effort

- Creating hope 
- Respecting power

- Building relationship

- Expressing enthusiasm

Teachers should give the students a reason for what they are learning and show them the importance of what they are learning. Teachers should look at the positive and build off mistakes. Creating hope involves "creating mountains that students believe they can climb". According to Barbara G. Davis (1993), the teacher creates an atmosphere that is open and positive. The classroom atmosphere plays an important role on student's life. Students may use any part of the classroom to complete their work. In most of these cases there is a great relationship between the teacher and the students when:

- the teacher moves next to the student when he/she talks or has any comment to say,

- the teacher sits with the students to discuss topics eye to eye,

- the teacher provides students with feedback,

- the teacher is patient with the students, and

- the teacher doesn't talk too much, uses the first 15 minutes of class for lectures or presentations, and then get the students working.

According to Weimer (2009), starting a lecture can be challenging because getting everyone seated, attentive, and ready to move forward with the content can take several minutes. The teacher's job is to find new strategies to engage students in learning. Many principles that can be considered important for good teaching are: the teacher must have the respect of his/her students. If they lose respect in the eyes of the student, they are destined to fail; and the teacher should sometimes be friendly with the student, so as to create a positive atmosphere.

Acccording to UKEssay (2015) teachers should design participation that requires the contribution of many, for example: small groups presenting brief reports, sharing examples or offering summaries. They should use hand motions, notes, etc., use normal English and stress intonation. They also should exemplify, by speaking in a clear way so that the student can understand what is said or what is meant. The teacher should not stand in only one place, he or she must move around the room standing next to as many different students as possible.

To make the lesson more interesting and more effective the teacher may also use memory strategies, which help students to store information, for example, creating mental links i.e. placing new words into context, applying images and sounds, practicing, analyzing and reasoning. It is important to note that we also have to use effective strategies that help students gain control over their own emotions and attitudes, encouraging them, and lowering anxiety.

Another teacher recommends some tips which make the first day and the rest of the semester successful. Weimer and Cassidy (2013) recommend noting the student's interests, to find out why students are enrolled in the course, how they feel about the subject, and what their expectations are. Then explain how the content and objectives of the course will help the students achieve their educational, professional, or personal goals. Give students options, let them decide between two opportunities or have them select which topics to explore in greater depth. Give students feedback as quickly as possible, that is, return papers and tests immediately. Give them some indications on how well they have done and how to improve.

Another important factor can be humor. According to UKEssay (2015) the contribution that humor makes to learning is well established in teaching. It is not that humor causes learning, but it helps to create conditions to learn something. It helps learners relax, avoids stress, and often makes it easier for students and teachers to connect personally. The presence of humor in a classroom can be very beneficial. Another important aspect of techniques and strategies is to understand the students. All students are not the same and they differ from one another. Some might be shy, other might be impulsive. Teachers should understand them in order to help them when needed. There are many factors that influence students, such as the physical and emotional climate of the student's home and neighborhood. Even if they have family problems or problems with their friends, teachers need to stay close to them and give advice. This means that sometimes teachers also have to play the role of a psychologist. This is a problem that affects our society a lot. 
Appropriate techniques and strategies in classes to build writing competency in English language

Keith (2008) noted that while speech has a greater range of non-verbal means to express meaning, writing will need a greater accuracy as the writer receives no immediate feedback. Writing is more precise and should be more accurate than speech. Bergstrom (1982) claims that, "As someone who teaches composition regularly and who is always aware of and interested in his students' writing, I have come to think that the most serious problem students have with their writing is a general inability to structure their thoughts with logical clarity". There are various stages of writing. At the first stage, writing is a mechanic process during which all the technical aspects of writing can be acquired. The second stage of writing can be called teaching composition which practically means individual creative work. According to Keith, Pritchard and Roesch (2006), there are four stages of teaching writing:

- Controlled - controlled writing activities are copying and dictation. It is a good idea to use copying in a way which encourages students to think. Copying is a challenging task during which the teacher writes a word or a sentence on the board, gives the students a few seconds to look at it and sees if the students can write it down

- Semi-controlled - fill-in exercises are useful activities, especially at the beginner stages. The purpose of this stage is to make students practice spelling and learn new vocabulary.

- Free-Free - these writing activities are to be prepared with warm-up and pre-writing activities. Students are asked to write down all the words and the expressions they can think of in connection with the topic. Picture descriptions or writing a report or an article can be a very good exercise.

- Expressive/creative - this type needs a lot of creativity and imagination. Students can be asked to write a short story, or an article based on their previous experience.

Appropriate techniques and strategies in classes to build speaking competency in English language

Writing and speaking belong to the output stage of language teaching process. When students are working on their language production, they are operating towards communication. Language production means that students are supposed to use all parts of a language at their disposal to achieve a communicative purpose. Brown (2007) believes that students should focus on both fluency and accuracy. Of all the four skills (listening, writing, speaking, reading), speaking seems to be the most important as people who know a language are referred to as 'speakers' of that language. Traditional classroom speaking practice often takes the form of drills in which one person asks a question and another gives an answer. The questions and the answer are predictable and often there is a correct alternative.

The purpose of asking and answering questions is to demonstrate the ability to ask and answer the question. Students think that the ability to speak a language is the product of language learning. To create classroom speaking activities that will develop communicative competence, teachers need to incorporate a purpose. Teachers help students develop speaking skills by making them aware of the different situations so that they can predict what they will hear and what they need to say in response. The importance of speaking has always been recognized but the various methods put different emphasis on it. Keith et al. (2008) believes that speaking can be developed through many sub-skills such as:

- organic basis of skills (articulation) - from sound formation to accurate respiration,

- rapid speech - to achieve fluent speech at the required speed,

- parts of speech - for a speaker it is necessary to have language competence including the categories mentioned above,

- collocation - a competent speaker has to be aware of the collocations used in the target language,

- stress/intonation - pronunciation close to that of native speakers whic learners are supposed to acquire,

- speech functions - students are expected to be aware of language patterns used in various communicative situations such as greetings and introductions,

- gestures/non-verbal means - a person who wants to communicate, are supposed to use nonverbal means as well such as facial expressions and gestures, 
- compensation strategies - while focusing on developing speaking skills, teachers are expected to prepare students for compensating their lack of knowledge in the act of speech, and

- coherence - if the speaker wants to deliver a speech, he is expected to connect the sentences and the paragraphs to make the text cohesive.

According to Keith et al. (2008) there are some activities that can improve speaking:

- Question-answers - students are expected to distinguish between given texts or pictures.

- Imitative performance (repetition) - in this case the procedure is to listen and repeat what is said.

- Intensive performance -the process of reading out loud.

- Extensive performance - monologue and retelling a story.

- Drama activities - the students are asked to listen and participate.

- Role play - this means repeating the words of certain characters in a story and at the same time add something new.

- Simulation - is a problem solving activity in which several students can take part.

- Memory games - this activity is very important for developing a students thinking.

- Debates - students can prepare for arguing for and against something.

Appropriate techniques and strategies in classes to build reading competency in English language

According To Lena (2010) reading is the fundamental skill upon which all education depend. Indeed the future success of all students relies upon their ability to become proficient readers. Reading is about understanding written texts. It is a complex activity that involves both perception and thought. It consists of two processes: word recognition and comprehension.

Word recognition refers to the written words. Comprehension is the process of making sense of words and sentences. Dilbeck (1995) believes that modeling reading for the students helps them see the strategies that are employ by the teacher while reading. Readers typically make use of background knowledge, experience with text and other strategies to help them understand the written text. According to Lena (2010), teaching reading requires considerable knowledge and skill, acquired over several years through practice. Children's interest in reading must be stimulated through regular exposure to interesting books and through discussions in which students respond to many kinds of texts. For best results, the teacher must instruct most students directly, keeping in mind the purpose of reading. The teacher must interpret errors, give corrective feedback, select examples to illustrate concepts, and explain new ideas in several ways. The teacher must be reflective and knowledgeable about the content they are teaching, that is, its relationship to meaning. Research has shown that good readers do not skim the text. They process the letters of each word in detail. There are many practical applications like:

- Teachers can provide opportunities for children to develop their language through story telling.

- Students should be encouraged to use language to express themselves while learning about books.

- What is also important to notice in reading in fluency. Fluency is important because it is closely related to comprehension. Fluency means being able to read the text accurately and quickly. Fluency also depends on the ability to group words appropriately during reading. This means, fluent readers recognize words quickly, but also know where to place emphasis or pause during reading. The reader must construct meaning from the recognized words. Guided practice in reading generally increases fluency. To assess fluency, teachers need to listen to their students reading out loud. They should provide feedback to the students about their reading.

Appropriate techniques and strategies in classes to build listening competency in English language

Berkley University (n.d.) noted that listening is the language modality that is used most frequently. It has been estimated that adults spend half of their communication time listening. O'Malley, Chamot, and Kupper (1987) views listening as an active process, in which individuals focus on selected aspects of input, construct meaning from passages and relate what they hear to existing knowledge.

According to Field (2009), one way to build listening is to use a simple dialogue. At first, students could listen for the main idea. Listening for main ideas means that the listener wants to get a general 
idea of what is being said. The details are less important. However, sometimes we need to listen for details, for example we need the details when we are getting directions to same place, like a friend's home. Another important reason for listening is listening and making inferences. Speakers do not always say exactly what they mean. An important aspect of meaning is that sometimes it is implied rather than stated.

\section{Methodology}

The methodology belongs to a quantitative data collection, which aims to measure the appropriate techniques and strategies for an effective class. The study gathered quantitative data from a large sample of teachers and facilitated the comparison of data. For conducting this study we used a variety of methods, starting with the literature review, and used questionnaires to survey teachers in the main English high school of Tirana.

Sample

For the collection of the data about the appropriate techniques and strategies for an effective class in "Asim Vokshi" High school, we decided to conduct our survey at the main English high school in the city of Tirana which is "Asim Vokshi" Secondary School. Since it is the main English high school in Tirana, the teachers and the students are from different cities and most of them have studied English, which means they are part of another culture and use different techniques and strategies. 70 students and 70 teachers were chosen.

After, we chose the number of population to be $70(\mathrm{~N}=70)$, we decided on the number of questionnaires that will be filled. Based on the formula, with the number of population being 70 , a $5 \%$ margin of error, and a $95 \%$ confidence level, the sample size was 55 .

Thus, the number of teachers and students who responded to questionnaires was 55 .

The sample used in this study is intentional (random) sample, as teachers who had at least five years of work experience in education.

Implementation of the data collection was conducted during May 2015 and consisted of:

- identification of the institutions where the data will be gathered, and

- implementation of data collection.

Instrument

Pre-prepared questionnaires were used, so they were not made by us. They questions were:

- Likert-type

- Yes/ No Question

- Circle the best option

\section{Findings and Discussion}

According to teachers, grammar reinforces vocabulary

Most of the teachers believe that this was a good method for strengthening students' capacity of learning and vocabulary reinforcement. Some of them used this kind of method, and they found it to be a good method.

According to students, writing skills/essays reinforces vocabulary

Most of the students believe that essays reinforce their vocabulary and provide original materials of the usage of language.

Our opinion

In our opinion, writing skills reinforce vocabulary because it helps students remember new words.

Teachers believe that using different examples for teaching techniques do not always lead to progress

Most of the teachers believe that the usage of different techniques in each class is nor a good way of teaching. They are supposed to be more focused more on techniques that rely on reading skills and fluency as it is more responsible for the way students uses the language and how fast they speak that language.

We believe teachers should use different techniques, include all the skills for an effective class and target all four skills, not just two of them. 
Reading skills help students acquire a foreign language

Half of the teachers believed that literary texts develop reading skills. Of course this is an effective way of making students read more about something as the more they read the better they become, not only at the foreign language but also intellectually. Most of the students find the idea of reading text in English very interesting. According to them it helps them learn vocabulary and become fluent in expressing thoughts in English.

In our opinion reading skill helps students to learn a foreign language.

English Plays

We noticed that most of students didn't like poetry, most of them have read stories, and a few read novels.

Only three students had read poetry, namely Shakespeare. As far as stories were concerned, one had read "Embrace the Night", another one had read "The Rich", another had read "The Observatory", and another read "The Count of Monte Cristo". From a total of 70 students, 50 of them had read stories. Three of them had read the novel "The Picture of Dorian Gray", one had read "Dollhouse", and two had read "Romeo and Juliet". Some other novels that had been read were: "Dead Men Don't Ski", "Juliet joins the Guide", "The Vow", "Shopaholic", "Street children", "Dear John", and "The Vampire Diaries".

According to teachers some techniques help students reinforce speaking

Most of the teachers say that different activities help student in reinforcing speaking. Most of them believe that different games and role-playing help students to improve speaking.

Half of the students were more attracted to DVD. They believed that this activity makes speaking more interesting and easier.

We share the same opinion as the teachers because role-playing is a really effective activity to develop speaking.

Teachers didn't like to exchange their materials

Most of the teachers didn't like to exchange their material. They prefer to get material from other sources. One teacher sayid "I would like to have different texts where I could make comparisons and make the best choices for my students, and at the same time contribute my ideas to my students. In doing so I would test the students and myself for a qualitative way of teaching".

Another teacher said "I would prefer to have different British and American materials".

More than half of the students wanted to read additional material in class because it improves their English by helping them expand their vocabulary and improve grammar. They think that teachers should share their materials in order to create vitality.

We share the same opinion, it is necessary to share materials and opinions to create vitality.

\section{Conclusion}

It is important to mention that education plays a crucial role in the dvelopment of society. Considering the importance of teaching, we focused our paper on the strategies and techniques of teaching.

In the research paper, we have included many strategies and techniques which are considered vital for effective teaching, based on material from well known authors who share their opinion about the process of teaching, and recommend some strategies and techniques for the teachers to follow.

Teaching strategies are methods used to allow learners to access the information the teacher is teaching. Some of them are: establishment of a good control over the class, creating a positive atmosphere where all students can feel free to express their own opinion, deciding what is important, essential and helpful for the students, and understanding what material attracts their interest so the most interesting topics can be involved which can be meaningful at the same time.

The questionnaire helped us understand the best way (techniques and strategies) for the acquisition of a second language. Teaching is an art, and as an artist, the teacher is required to deal with different situations and students. 


\section{References}

Bergstrom, R. F. (1982). Piaget and Teaching composition, Chapter 10.

Brown, H. D. (2007). Teaching by Principles: An Interactive Approach to Language Pedagogy.

Davis. G.B . (1993), Tools for Teaching.

Dilbeck, D. (1995). Journey to reading theories.

Field, J. (2009). "Listening in the Language Classroom" Cmbridger Language Teaching Library. Retrieved by www.cambridge.org.br

Greive, D. (1992). Teaching Strategies \& Techniques for Adjunct Faculty, Third Edition, Higher Education.

Keith, J., Pritchard, T., \& Roesch, B. (2008). Teaching strategies and motivation. Retrieved December 2015 from dspace.sunyconnect.suny.edu

Lena, M. (2010). "How to teach Reading”. Retrieved by http://martalenabanurea.blogspot.al/

Mendler, A. N. (2000). Motivating students who don't care, Successful techniques for educators.

Noddings, N. (2003). Journal of Philosophy of Education, Vol. 37, No. 2. "Is Teaching a Practice".

O’Malley, J. M., Chamot, A. U., \& Kupper, L. (1987). The role of learning strategies in second languages acquisition. Retrieved October 2015 from library.iugaza.edu.ps

UKEssay (2015). Can Effective Relationships Be Constructed Education Essay; Teacher's behavior and students motivation for learning education essay. Retrieved September 2015 from: www.ukessays.com

University of Berkley (n.d.) Precursors to language: The first 18 months of life. Retrieved by www.berkeley.edu

University of Phoenix (2011) Effective Classroom Management Plan; Education AED/203. Retrieved January 2016 from www.coursehero.com

Weimer, M. (2009). Effective Teaching Strategies: Six Keys to Classroom Excellence; Excerpted from Effective Teaching: Six Keys to Success, The Teaching Professor, March 2006. Retrieved February 2016 from http://www.facultyfocus.com

Weimer.M, \& Cassidy.A. (2013). Teaching Strategies for the College Classroom: A Collection of Faculty Articles. Retrieved by: www.magnapubs.com 